\title{
Double cutter face milling of spiral bevel gears
}

\author{
Ryspek Usubamatov*, Nor Zaiazmin Yahaya \\ School of Manufacturing Engineering, University Malaysia Perlis, Arau, Malaysia
}

Email address:

ryspek@unimap.edu.my (R. Usubamatov), zaiazmin@unimap.edu.my (N. Z. Yahaya)

\section{To cite this article:}

Ryspek Usubamatov, Nor Zaiazmin Yahaya. Double Cutter Face Milling of Spiral Bevel Gears. International Journal of Science, Technology and Society. Special Issue: Technology Transfer. Vol. 3, No. 1-1, 2015, pp. 10-16. doi: 10.11648/j.ijsts.s.2015030101.12

\begin{abstract}
In manufacturing area, one of the most complex technological processes is the machining of spiral bevel gears. For these processes, special machine tools designed with peculiar manuals for calculating the gear geometry, and the setting-up processes were developed. The known technologies and design of gear-cutting machine tools are different and based on processes that cut the concave and convex sides of the spiral tooth separately or simultaneously. These processes are different in productivity and quality of gear machining. Due to these circumstances, manufacturers created many modifications, with different qualities of the gear-cutting processes. Presently, there are following technologies: continuous indexing (face-hobbing) and single indexing (face-milling) that unlimitedly available to the user. This paper presents a new face-milling process of machining spiral bevel gears that can increase productivity and improve the quality of gears. The new process presents a solution that uses two cutter heads simultaneously for machining both concave and convex sides of the spiral teeth. Manufacturers can accept the new technology of the spiral bevel gear that needs a wide spectrum of research to get optimal solutions.
\end{abstract}

Keywords: Cutter Head, Spiral Teeth, Gear, Technology

\section{Introduction}

Spiral bevel gears are one of the most complex components in mechanical engineering, and special machines, and tools have therefore been required to make them. Known technological processes as face hobbing, cyclo-palloid, and face milling are applied for machining the spiral bevel and hypoid gears. These processes are characterized by different attributes of productivity and quality, use different tools and applied for different gear designs [1-2]. There are highly productive technological processes that enable to cut qualitatively both sides of the spiral teeth using one cutter on a wheel and a pinion. Face-hobbing and cyclo-palloid technologies are continuous processes of high productivity [3, 4]. Face-milling technologies are single indexing process enable cutting concave and convex sides of the tooth simultaneously or separately, but less in productivity [2]. There are several intermediate processes for machining spiral bevel gears that use combinations of the above-mentioned gear cutting systems. These processes use different correction methods, tool set up and tuning systems. Whether facehobbing or face- milling should be used cannot be answered with a simple yes or no. It depends on the intended use of the respective gear [4].
Technological processes and gear-cutting machine tools of different designs and with $\mathrm{CNC}$ systems have advantages and disadvantages [5]. These technologies are based on the use the flat or conical gear generating system with different number of set up processes for machining sides of the spiral teeth. The first mode of processing is simple in the design of the machine tool, but does not generate a good tooth shape and needs correction systems that enable getting the appropriate shape of the spiral tooth. The second mode is more complex in the design of the gear cutter machine tool, but produced good shapes of teeth [1-4].

All of these processes have defined areas of application. Numerous publications in area of machining spiral bevel gears confirm that not all processes are perfect and researchers propose improvements for gear technologies. Analysis of publications shows gear manufacturing needs new solutions, which can provide high productivity, minimum cost and high quality of gear tooth with minimum corrections. There are many publications dedicated to modelling of face-hobbing processes with aim to enhance the quality of gear machining by different corrections of the tooth shape [6-8]. Other publications considering machining gears based on cyclo-palloid processes [9-10]. A several publications conduct analysis and evaluation of face-hobbing 
and face-milling machining the bevel gears by criterions of quality and efficiency [10-11]. Traditional single indexing face-milling processes are still under consideration of the researchers that modelling and improving this gear technology [12]. A several computer-aided methods for teeth generation and modelling of gear-cutting processes was developed and applied to solve problems in enhancing productivity and quality of gear-cutting processes [13-14].

This paper presents a new solution for face-milling the spiral bevel gears that can increase productive and improve quality. The new technology enables the machining simultaneously the concave and convex sides of the spiral (circular) teeth by two cutter heads and needs further development for practical realization. Proposed process is similar to cyclo-palloid process, which is based on application of face-hobbing cuter heads. However, there is the difference between epicycloid and circle teeth that is still an important basis for the minimization of the difference.

\section{Methodology}

Double cutter face-milling technology can machine spiral bevel gears with tooth standard depth taper and uniform depth and uses only one tool set up process for processing of a wheel and pinion. Traditional face-milling technology can machine two sides of teeth for constant and modified slot width of bevel gears. However, machining these gears needs special corrections of the processes, but decreases the idle set up and tuning time quite essentially.

Proposed face-milling technology is based on the use of two cutter heads, which requires a new design of the spindle unit. Generally new technology is same as known facemilling process for machining spiral bevel gear and can be used with flat or conical generating gears. Sketch of new technology represented in Fig. 1 that depicts cutters 2 and 4 located on cutter heads 1 and 3 with ledges 5 and cavities 6 , which have clearances that enable avoid contacts of the rotating tools.

At the initial position, the two cutter heads with axes $C_{1}$ and $C_{2}$, should locate co-axially (Fig. 1a) with following set up the axial eccentricity (Fig. 1b).

The kinematics of the double spindle unit and the spiral bevel gear need new design of the machine tool that enables to keep a relative location of the cutters to the gear blank during the machining process. The proposed technology is represented in the following sketches (Fig. 1).

The spiral teeth generating process is represented in the system of axes $\Sigma o, x, y$ (Fig. 1c). The double spindle unit receives the angular velocity $\omega$ around the datum point, and the gear blank rotates with an angular velocity $\gamma$. The cutting process occurs by two cutter heads 1 and 3 with an equal angular velocity $n$ and in one direction. The equal narrowing slot on the blank gear is created by the displacement of the spindle axes $C_{1}$ and $C_{2}$ on distance $g$ (Fig. 1b).

The designs of the double spindle units can be represented by different constructions and one variant is represented in Fig. 2. This spindle unit consists: the cutter heads 1 and 2 placed on the spindles 3 and 4, which fitted in housings 6 and 5 accordingly. The spindles 3 and 4 are driven by gears 7, 8, $9,11,12$ and 13 that provide the equal angular velocity for spindles. The pinion 12 is located on the movable levers 14 and 15. Such a design enables provide displacement of the housing 5 (grey colour) with respect to the housing 6 that enable to get eccentricity $g$ (Fig. 1b) by the clearanceless mechanism for the displacement 16 . This type spindle unit can be embedded into spiral gear machine tools.

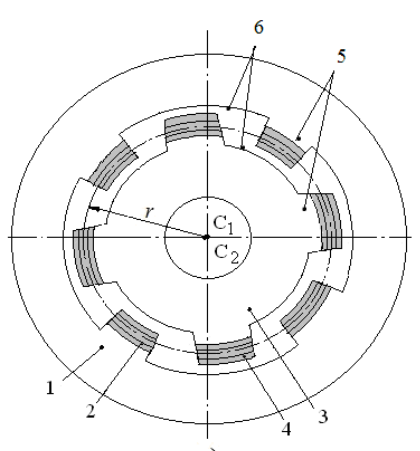

a)

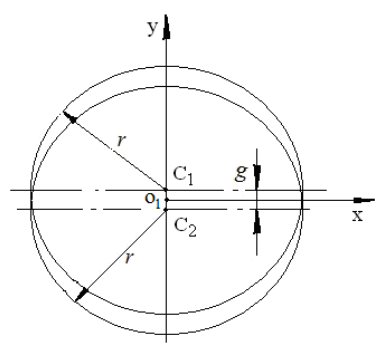

b)

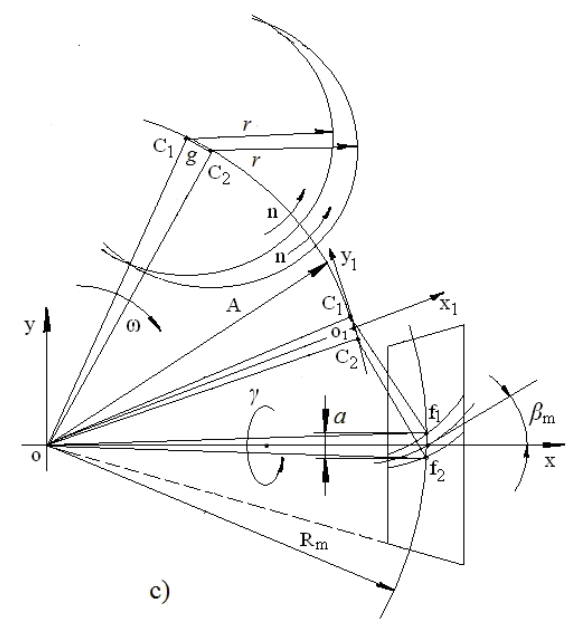

Figure 1. Sketch of machining spiral teeth with two cutter heads.
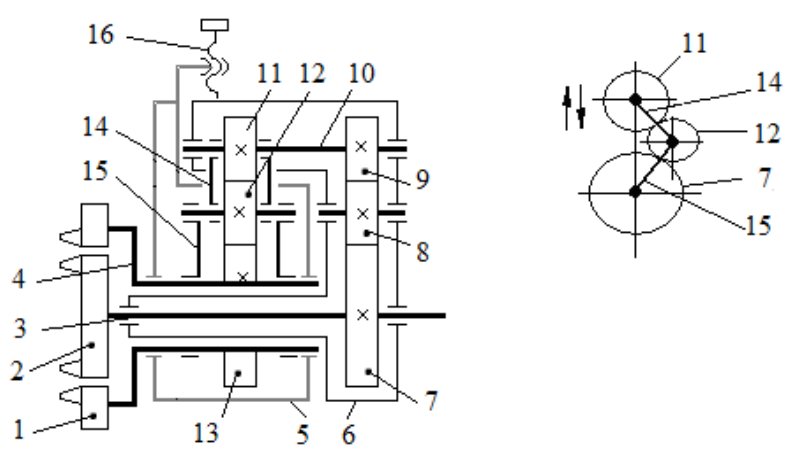

Figure 2. Double spindle unit for the spiral bevel gear machining.

The value of the radial displacement for the spindles' axes depends on the geometry of the spiral bevel gear. The spindles' eccentricity $g$ is calculated by the displacement distance $a$ of two cutters. The distance $a$ is the difference between the size $e_{\mathrm{tm}}$ of the chordal pitch width of the tooth slot and the pitch width $S$ of the cutter's teeth is represented 
by the following equation (Fig. 3a):

$$
\begin{aligned}
& a=e_{t m}-\frac{S}{2} \cos \left(\beta_{m}+\frac{\varepsilon}{2}\right)-\frac{S}{2} \cos \left(\beta_{m}-\frac{\varepsilon}{2}\right)= \\
& e_{t m}-\frac{S}{2}\left[\cos \left(\beta_{m}+\frac{\varepsilon}{2}\right)+\cos \left(\beta_{m}-\frac{\varepsilon}{2}\right)\right]
\end{aligned}
$$

where $a$ is displace distance of two cutters, $e_{\mathrm{tm}}$ is the mean chordal width of tooth slot on pitch cone, $S$ is the of cutter's teeth width, $\beta_{\mathrm{m}}$ is the mean spiral angle, and $\varepsilon$ is the angle of the tooth narrowing on the pitch cone.

The formula in the square brackets of Eq. 1 can be replaced by the trigonometric identity of the cosine sum

$\cos \alpha+\cos \beta=2 \cos [(\alpha+\beta) / 2] \times \cos [(\alpha-\beta) / 2]$ [12]. After, transformation and simplification the equation of the cutters' displacement has the following equation:

$$
a=e_{t m}-S \cos \beta_{m} \cos (\varepsilon / 2)
$$

The angle $\varepsilon$ of the spiral slot (tooth) narrowing is computed from the symmetrical triangle $o h_{1} h_{2}$ (Fig. 3b) and represented by the following equation.

$$
\varepsilon=\arcsin \left(e_{t m} / 2 R_{\mathrm{m}}\right)
$$

where the distance of $o h_{1}$ is the mean cone distance $R_{\mathrm{m}}$ (Fig. $1 c)$, other parameters are as specified above.

Substituting Eq. (3) into Eq. (2) and transformation gives the following equation.

$$
\mathrm{a}=\mathrm{e}_{\mathrm{tm}}-\mathrm{S} \cos \beta_{\mathrm{m}} \cos \left(\frac{\arcsin \left[\mathrm{e}_{\mathrm{tm}} / 2 \mathrm{R}_{\mathrm{m}}\right]}{2}\right)
$$

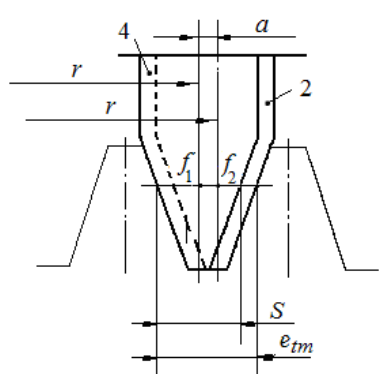

a)

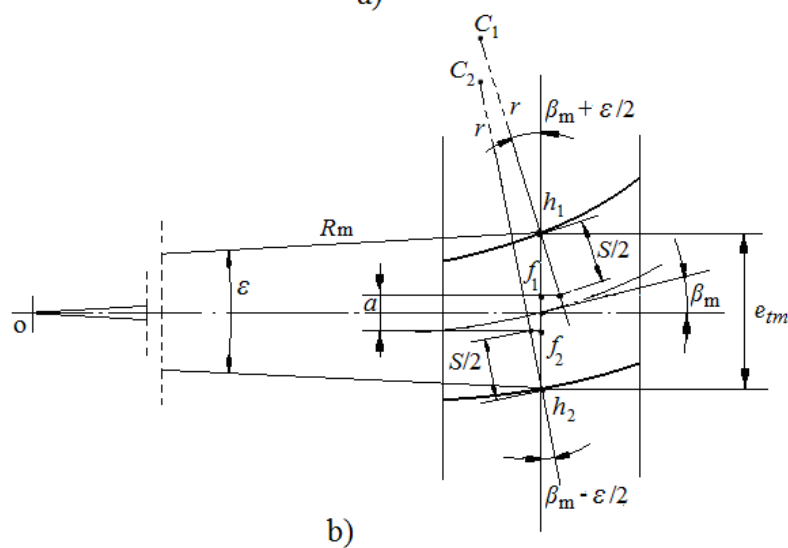

b)

Figure 3. The cutters'displacement
The length of spindle axe's displacement $g$ (Fig. $1 b, c)$ is calculated from the triangle $o C_{1} C_{2}$, where $A$ is the radius of the spindle axis motion. The triangle $o f_{1} f_{2}$ is similar to the triangle $o C_{1} C_{2}$, and then by the theorem of similarity the distance $g$ is represented by the following equation.

$$
\mathrm{g}=\mathrm{a} \frac{\mathrm{A}}{\mathrm{R}_{\mathrm{m}}}=\frac{\mathrm{A}}{\mathrm{R}_{\mathrm{m}}}\left\{\mathrm{e}_{\mathrm{tm}}-\mathrm{S} \cos \beta_{\mathrm{m}} \cos \left(\frac{\arcsin \left[\mathrm{e}_{\mathrm{tm}} / 2 \mathrm{R}_{\mathrm{m}}\right]}{2}\right)\right\}
$$

Practically, the displacement $a$ of cutters has small value. For average size of the gear, the displacement $a$ can be around $1.0 \ldots 2.0 \mathrm{~mm}$. Hence, the size of the radius $A$ of the spindle axis location will be a little bit different that leads on the change of the mean spiral angle $\beta_{\mathrm{m}}$. The height of the segment of the arc length $\mathrm{C}_{1} \mathrm{C}_{2}$ with chord $g$ (Fig. 1c) is around $1.0 \mu \mathrm{m} \ldots 5.0 \mu \mathrm{m}$ that changes of the angle $\beta_{\mathrm{m}}$ value on $0.07^{\prime \prime} \ldots 0.2^{\prime \prime}$, which can be neglected due to the small value.

Processing the bevel gears on a CNC machine tool needs to establish the initial axes system. Furthermore, it is necessary to establish the new centre of the two axes of the double spindle unit. This new centre $o_{1}$ should be the middle point between the two centres $C_{1}$ (fixed spindle) and $C_{2}$ (movable spindle) (Fig. 1b). The new centre $o_{1}$ belongs to the new rated axis for double spindle unit. Practically, the rated axis sets up at the point $o$ that is the pitch cone apex of the bevel gear and then displaces next to the point $o_{1}$ according to the mean spiral angle $\beta_{\mathrm{m}}$. To get exact geometry of the teeth, the rated axis should be located on distance $g / 2$ relative to the fixed axis of the spindle unit. The rated axis $o_{1}$ of the spindle unit should be inserted in software for the following use.

The sketch for calculation of the bevel gear machining motions in the system of axes $\Sigma o, x, y, z$ is presented in Fig. 4. For machining the spiral teeth, the rated axis of the spindle unit $o_{1}$ should move by the radius $A$, which depends on the mean spiral angle $\beta_{\mathrm{m}}$. The location of the rated axis of the spindle $o_{1}$ is represented in the axis system of $\Sigma o x y z$ by the following equations:

$$
\begin{aligned}
& X_{o}=A \cos \varphi ; \\
& Y_{o}=A \sin \varphi
\end{aligned}
$$

where $X_{o}$ and $Y_{o}$ are linear coordinates of the spindle rated axis $o_{1}$ in the axis system $\Sigma o x y z$, $A$ is the radius of motion of the spindle axis, $\varphi$ is angular coordinate of the radius $A$.

The double cutter machining of the spiral bevel gear needs continuous orientation of the centres, $C_{1}$ and $C_{2}$, with respect to the pitch diameter of the gear blank. The chordal line $C_{l} C_{2}$ of the spindle unit must be always tangential to the circle line of the spindle motion. The new machining process needs modification of the axes system $\Sigma o x y$ with the new axes system $\Sigma o_{1} x_{1} y_{1}$ (Fig. 4) that is defined by the method of transformation of coordinates under translation and rotation of axes. 


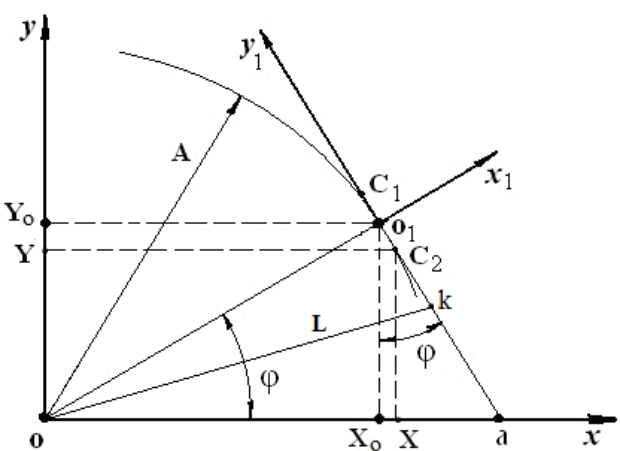

Figure 4. Transformation of Cartesian axes under translation and rotation of axes.

The Cartesian axes system $\sum o x y$ is the first axes system of a machine tool. The second axes system $\sum o_{l} x_{1} y_{1}$ is the system of the double spindle unit. The first axis system is taken to the second by the transformation of the origin system $\sum$ oxy to the origin system $\sum o_{1} x_{1} y_{1}$ followed by the rotation of the system around the point $o_{1}$ on the angle $\varphi$ (Fig. 4). The point $C_{2}$ has the coordinates $(X, Y)$ in the axes system Eoxy and coordinates $\left(C_{2}, o_{1}\right)$ in the axes system $\sum o_{1} x_{1} y_{1}$. The transformation of

Cartesian axis by the parallel translation and rotation of axes is given by the equations:

$$
\begin{aligned}
& X=X_{\mathrm{o}}+C_{2} \sin \varphi \\
& Y=Y_{\mathrm{o}}-C_{2} \cos \varphi
\end{aligned}
$$

where $X_{\mathrm{o}}$, and $Y_{\mathrm{o}}$ represented by Eq. (6), $C_{2}$ is represented in the coordinate system $\sum o_{1} x_{1} y_{1}$ and replaced by the half of the length of the cutter displacement $C_{2} O_{1}=g / 2$ (Fig. 1b), $g$ is represented by the Eq. (5); other parameters are as specified above.

Substituting of defined parameters into Eq. (7) gives the following equations:

$$
\begin{aligned}
& X=A \cos \varphi+(\mathrm{g} / 2) \sin \varphi \\
& Y=A \sin \varphi-(\mathrm{g} / 2) \cos \varphi
\end{aligned}
$$

where all parameters are as specified above.

\section{Case Study, Computer Modeling and Set up Process}

The known mathematical model of motions by three axes interpolation represented by the following equations (Fig. 5):

$$
\begin{gathered}
X(t)=A \cos \varphi(t) \\
Y(t)=A \sin \varphi(\mathrm{t}) \\
Z(t)=0 \\
\gamma(t)= \pm \varphi(t) \cos \theta_{f} / \sin \delta
\end{gathered}
$$

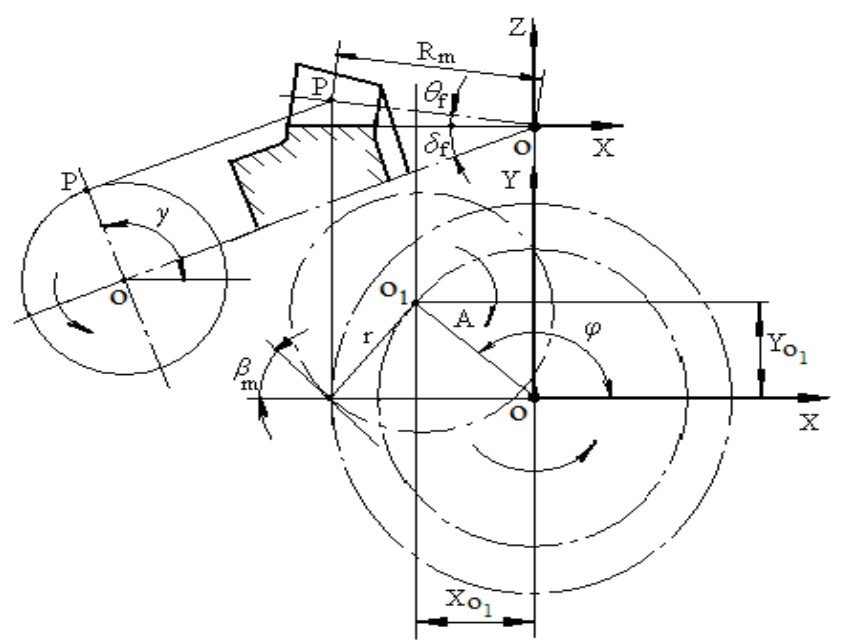

Figure 5. Sketch for calculation of the bevel gear machining motions.

where $X(t), Y(t)$, and $Z(t)$ are linear motions of the axis of the spindle; the axis $Z$ needs the set up motions only; $A=\sqrt{r^{2}+\left(R_{m} \cos \theta_{f}\right)^{2}-2 r R_{m} \cos \theta_{f} \sin \beta_{n}} ; r$ is mean radius of the cutters on the cutter head, $\theta_{f}$ is the dedendum angle; $\beta_{n}$ is the mean spiral angle at dedendum cone, $\varphi(t)$ is angular motion of the spindle's centre $o_{1} ; \delta$ is the pitch angle; $\gamma(t)$ is angular motion of the gear blank, signs $( \pm)$ at formula $\gamma(t)$ are the upper sign belongs to the right spiral tooth and counterclockwise rotation of the blank, and the lower sign for the left spiral tooth and clockwise rotation of the blank; other parameters are as specified above.

Replacing Eqs. (9) by Eqs. (8) and transforming gives the new system of equations for machining of spiral bevel gears by two cutter heads.

$$
\begin{gathered}
X(t)=A \cos \varphi(t)+(g / 2) \sin \varphi(t) \\
Y(t)=A \sin \varphi(t)-(g / 2) \cos \varphi(t) \\
Z(t)=0 \\
\gamma(t)= \pm \varphi(t) \cos \theta_{f} / \sin \delta
\end{gathered}
$$

where all parameters are as specified above.

Eq. (10) enables programming the machining process of spiral bevel gears by the two cutter heads on multi-axis CNC machine tools and performs continuous change of orientation of the double spindle unit with respect to the gear blank.

The Computer modeling of Eq. (10) is conducted by the MATLAB software, which used an interpolation by the three axes $(X, Y$ and $\gamma)$. The initial machining parameters of the spiral bevel gear are presented in the Table 1.

Substituting the parameters into Eq. (10) and transforming gives the following equations:

$$
\begin{gathered}
X(t)=39.728975 \cos \varphi(t)+0.016218 \sin \varphi(t) \\
Y(t)=39.728975 \sin \varphi(t)-0.016218 \cos \varphi(t) \\
\gamma(t)= \pm 1.410523 \varphi(t)
\end{gathered}
$$


The equations $X(t)$ and $Y(t)$ content two components, which is the first represents circular motion of the spindle axis $o_{1}$ around the centre $o$, i.e., pitch cone apex of the bevel gear (Figs. 1, 4, 5).

Table 1. The initial machining parameters of spirsal bevel gear

\begin{tabular}{lllll}
\hline $\mathbf{A}, \mathbf{m m}$ & $\boldsymbol{\theta}_{\mathbf{f}}$ & Table & $\mathbf{S}, \mathbf{m m}$ & $\underline{\boldsymbol{e}}_{\mathbf{t m}}, \mathbf{m m}$ \\
\hline 39.728975 & $4.14^{0}$ & 41.5 & 3.5 & 3.775 \\
\hline \multicolumn{6}{c}{} \\
\hline $\mathbf{g}, \mathbf{m m}$ & $\boldsymbol{\delta}$ & $\boldsymbol{\beta}_{\mathbf{m}}$ & $\boldsymbol{\beta}_{\mathbf{n}}$ \\
\hline 0.032436 & $45^{0}$ & $35^{0} \cos 4.14^{0}=34.908^{0}$ & $35^{0}$ \\
\hline
\end{tabular}

Second components represent the turn of the line $C_{1} C_{2}$ around spindle axis $o_{1}$ during its circular motion. This turn motion enables to keep the spindle axis line $C_{1} C_{2}$ tangentially to the circular line of the spindle axis $o_{1}$ motion (Figs. 1, 4).

The value of the cutters' centre's displacement $\mathrm{g} / 2=$ $0.016218 \mathrm{~mm}$ is small for the visual presentation of the centre line $C_{1} C_{2}$ tangential location (Fig. 1). The line $C_{1} C_{2}$ can be presented by any segment with the arbitrary value, for example $o_{1} k=15.0 \mathrm{~mm}$ (Fig. 4 ). Then, Eq. (11) is presented by the following equations :

$$
\begin{gathered}
X(t)=39.728975 \cos \varphi(t)+15.0 \sin \varphi(t) \\
Y(t)=39.728975 \sin \varphi(t)-15.0 \cos \varphi(t) \\
\gamma(t)=1.410523 \varphi(t)
\end{gathered}
$$

Graphical and numerical solutions of the bevel gear processing by Eq. (12) is presented in Fig. 6 and Table 2. Fig. 6 and Table 2 depict the relationship between $X(t)$ and $Y(t)$, and show the motions of the spindle unit is circular and the centre line $C_{1} C_{2}$ of the spindle unit is permanently tangential to the circular curve motion of the spindle axis $o_{1}$. The permanent tangential location of the centre line $C_{1} C_{2}$ enables to maintain the mean spiral angle $\beta_{\mathrm{m}}$ in process of the machining the concave and convex sides of the spiral teeth by two cutters simultaneously. Table 2 presents the numerical results for several locations of the cutter's centre $C_{2}$. The radius of circular motion of the centre $C_{2}$ is calculated by the following equation:

$$
L=\sqrt{[X(t)]^{2}+[Y(t)]^{2}}=\sqrt{(-17.485)^{2}+38.698^{2}}=42.466 \mathrm{~mm}
$$

where the values for $X(\mathrm{t})$ and $Y(\mathrm{t})$ present the location of the centre $C_{2}$ at the angle $\varphi=135^{\circ}$.

This radius can be calculated by values of the radius $A=$ $39.729 \mathrm{~mm}$ and by the segment $o_{1} k=l=15.0 \mathrm{~mm}$ (Figs. 4, 6),

$$
L=\sqrt{A^{2}+l^{2}}=\sqrt{39.729^{2}+15.0^{2}}=42.466 \mathrm{~mm}
$$

Table 2. Numerical results of interpolation by three axes $X, Y$ and $\gamma$

\begin{tabular}{llllll}
\hline $\boldsymbol{\varphi}^{\mathbf{0}}$ & $\mathbf{X}_{\mathbf{1}}(\mathbf{t}), \mathbf{m m}$ & $\mathbf{Y}_{\mathbf{1}}(\mathbf{t}), \mathbf{m m}$ & $\mathbf{X}(\mathbf{t}), \mathbf{m m}$ & $\mathbf{Y}(\mathbf{t}), \mathbf{m m}$ & $\boldsymbol{\gamma}^{\mathbf{0}}$ \\
\hline 90 & 0.000 & 39.729 & 15.000 & 39.729 & 126.947 \\
105 & -10.282 & 38.375 & 4.206 & 42.257 & 148.105 \\
120 & -19.879 & 34.406 & -6.888 & 41.906 & 169.263 \\
135 & -28.092 & 28.092 & -17.485 & 38.698 & 190.421 \\
150 & -34.406 & 19.879 & -26.906 & 32.869 & 211.578 \\
165 & -38.375 & 10.282 & -34.492 & 24.770 & 232.736 \\
180 & -39.729 & 0.000 & -39.729 & 15.000 & 253.894 \\
\hline
\end{tabular}

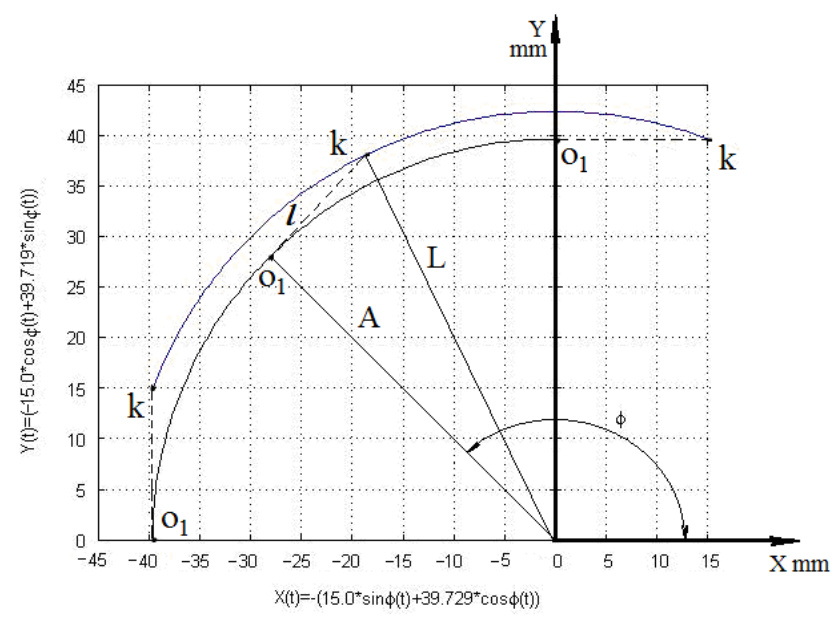

Figure 6. Circular interpolation of liner motions by the axes $X$ and $Y$.

Processing on $\mathrm{CNC}$ machine tools needs coordinated orientation of the spindle with respect to the bevel gear blank and establish a datum point, which the cross point of the gear and spindle axes. Orientation is conducted by the contact method of measurements for the set up and tuning processes. The datum point is accepted the pitch cone apex $O$ of the bevel gear that is defined by measurements of distances to the face spindle surface, the face surface of the rotary table and cylindrical surface of the gear blank mandrel (Fig. 7).

Methodology of the set up and measurement processes are included the following steps:

1 The touch point sensor is fitted into the fixed spindle (Fig. 2, Fig. 7).

2 The bevel gear mandrel is fitted onto the rotary table, which inclined on the root angle of the bevel gear. The upper dedendum cone line of the gear should be parallel to the axis OX and locates in the plane of XOZ.

3 The touch point sensor being moved by the axis OY and touched with the cylindrical surface of the mandrel. It is recorded the input from touch by the axes $\mathrm{OX}_{1}, \mathrm{OY}_{1}$ and $\mathrm{OZ}_{1}$, (sensor location 1).

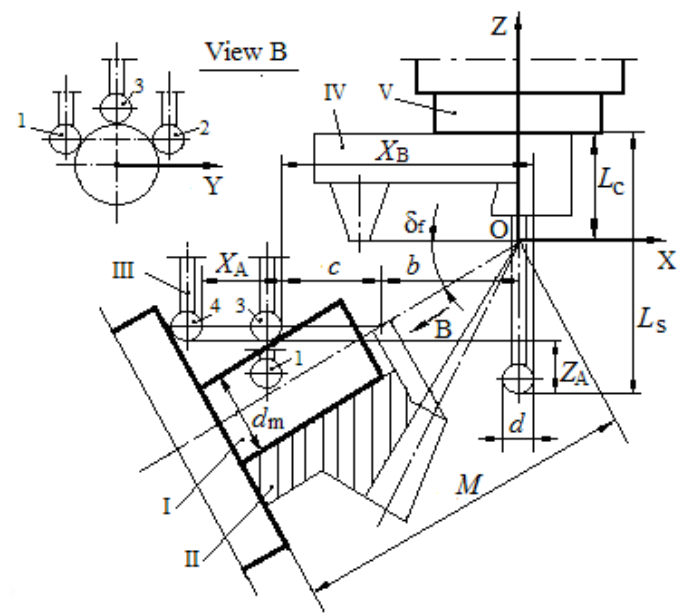

Figure 7. Schema of the datum point set up process. I-mandrel installed on the rotary table unit; II - bevel gear; III - touch point sensor; IV - cutter head; $V$ - spindle unit. 
4 The touch point sensor being moved consistently:

- by the axis $\mathrm{OZ}$ on distance over the surface of the mandrel,

- by the axis OY on distance bigger than the mandrel diameter $d_{m}$

- by the axis $\mathrm{OZ}$ down on distance with the recorded data of axis $\mathrm{OZ}_{1}$ (stage 3),

- by the axis OY back and to touch with the cylindrical surface of the mandrel. It is recorded the input from touch by the axis $\mathrm{OY}_{2}$ (sensor location 2).

5 The dates $\mathrm{OY}_{1}$ and $\mathrm{OY}_{2}$ of the sensor location enable to calculate the data $\mathrm{OY}_{3}=\left(\mathrm{OY}_{1}+\mathrm{OY}_{2}\right) / 2$, through which passes the plane $\mathrm{XOZ}$ of the datum point.

6 The touch point sensor being moved consistently:

- by the axis OZ over the surface of the mandrel and moved by the axis $\mathrm{OY}$ to the input data $\mathrm{OY}_{3}$ calculated above,

- by the axis $\mathrm{OZ}$ down to touch with the cylindrical surface of the mandrel. It is recorded the input from touch by the axes $\mathrm{OX}_{2}$ and $\mathrm{OZ}_{2}$ (sensor location 3),

- by the axis OX from the mandrel and touch the face surface of the rotating table. It is recorded the input from touch by the axis $\mathrm{OX}_{3}$ (sensor location 4),

7 The sensor location with dates $\mathrm{OX}_{3}, \mathrm{OY}_{3}$ and $\mathrm{OZ}_{2}$ enables to calculate the axial motions to set up the datum point (Fig. 7):

- the distance $X_{A}=\left|O X_{3}-O X_{2}\right|$

- the distance $X_{b}=c+b+d / 2$,

where $c=\left[d\left(1-\sin \delta_{\mathrm{f}}\right)+d_{\mathrm{m}}\right] / 2 \sin \delta_{\mathrm{f}}$,

$b=\left\{\mathrm{M}-\left[\left[d\left(1-\cos \delta_{\mathrm{f}}\right) / 2+X_{\mathrm{A}}+d\right] \cos \delta_{\mathrm{f}}\right\} \cos \delta_{\mathrm{f}}\right.$,

$d$ - sensor's ball diameter, $d_{\mathrm{m}}-$ mandrel diameter,

$M$ - mounting distance

- the distance $Z_{\mathrm{A}}=L_{\mathrm{s}}-L_{\mathrm{c}}-b \operatorname{tg} \delta_{\mathrm{f}}-d / 2$, where $L_{\mathrm{s}}$ is the distance from the face side of the spindle to the tip of the sensor's ball, $L_{\mathrm{c}}$ is the distance from the face side of the spindle to the tips of the milling cutters.

8 The touch point sensor being moved up by the axis $\mathrm{OZ}$ for the following free motions.

9 The touch point sensor being moved away from the spindle unit and two milling head cutters are fitted into spindles.

10 The bevel gear blank is fitted on the mandrel.

11 The spindle with the milling cutter heads being moved consistently:

by the axis $\mathrm{OX}$ to the recorded input data $\mathrm{OX}_{3}, \mathrm{OY}_{3}$

- by the axis $O X$ to the side of the pitch cone apex on the distance $\mathrm{X}_{\mathrm{A}}+\mathrm{X}_{\mathrm{B}}$. It is recorded the input of the datum point $\mathrm{OX}_{4}$

by the axis OY to the distance $g / 2$ (Fig. 1, Eq. (5)). It is recorded the input of the datum point $\mathrm{OY}_{4}$.

. by the axis $\mathrm{OZ}$ down to the recorded data $\mathrm{OZ}_{2}$, then on the distance $Z_{\mathrm{A}}$. It is recorded the input of the datum point $\mathrm{OZ}_{3}$

12 The data of $\mathrm{OX}_{4}, \mathrm{OY}_{4}$ and $\mathrm{OZ}_{3}$ is the datum point for the double spindles with the head cutters and the crossing point of the rated axis of spindle unit and bevel gear axis.

\section{Results and Discussion}

The article represented the mathematical model of a new technology for machining spiral bevel gears by two cutter heads. This face-milling process enables to cut the concave and convex sides of the spiral teeth simultaneously. Proposed model enables the development and design of new types of spiral bevel gear-cutting machine tools, which should have two co-axial spindle units with the ability to set up their axial eccentricity. For processing the spiral bevel gears on the multi-axis $\mathrm{CNC}$ machine tools, the double spindle unit should be used. New technology can increase the productivity and quality of gear for single indexing facemilling processes. Furthermore, the new mathematical model can be used to develop additional set up processes for tuning the bevel gear-generating machine units. Eq. (5) enables the calculation of the setup displacement of the double spindle axes for simultaneous machining concave and convex sides of the teeth. Eqs. (10) enable the derivation of program software for $\mathrm{CNC}$ machine tools and the calculation the coordinated location of the double spindle unit. Further calculations of the technological process for machining of the spiral bevel gear should be conducted by known modes on special gear-generating machine tools and $\mathrm{CNC}$ machining centers.

\section{Conclusion}

The paper represents mathematical proposal for machining spiral bevel gears that use special design of the two cutter heads and double co-axial spindle unit. This new technology enables to cut concave and convex sides of the spiral tooth simultaneously for bevel gears with tooth standard depth taper and uniform depth. This gear geometry is accurate than gear with constant or modified slot width. The new process enables the fulfilment of a single set up process of the double spindle unit and the blank for the machining the spiral bevel wheel and pinion. It can increase productivity of single indexing face-milling process due to decreasing the time for tuning process and machining of both sides of spiral teeth. These properties are very important for manufacturers. Results of this paper can be used in the project stage of developing new technological processes and design of new types of machine tools for generating hypoid and bevel gears with spiral teeth.

\section{Nomenclature}

$A$ - radius of the spindles' basic axis circular motion

$C_{1}$ - centre and axis of the basic spindle with the head cutters 3

$C_{2}$ - centre and axis of the movable spindle with the head cutters 1

$M$ - mounting distance

$R_{m}$ - mean cone distance

$S$ - pitch width of cutter's tooth

$X, Y$ and $Z$ are linear coordinates of a spindle unit center or axis $X(t), Y(t)$, and $Z(t)$ are linear motions of an axis of the spindle 
$d$-sensor's ball diameter

$d_{\mathrm{m}}$ - mandrel diameter

$e_{\mathrm{tm}}-$ mean chordal pitch width

$f_{1} ; f_{2}$-points of intersection of the circle of the mean cone distance $R_{\mathrm{m}}$ with the cutters' axes of symmetry.

$g$ - displacement of the spindles' axis

$n$ - angular velocity of spindles

$o_{1}$ - rated axis and centre

$r$ - mean radius of the cutters

$\beta_{\mathrm{m}}$ - mean spiral angle

$\beta_{n}$ - mean spiral angle on the dedendum cone

$\gamma(t)$ - angular motion of a gear blank

$\delta$ - pitch angle

$\varepsilon$ - angle of the tooth narrowing on the pitch cone

$\theta_{f}$ - dedendum angle

$\varphi$ - angular coordinate of radius $A$

$\varphi(t)$ - angular motion of the spindle's centre

$\omega$ - angular velocity of spindle's axis around the datum point

\section{Acknowledgements}

This research article is under Fundamental Research Grant Scheme fund of Malaysian Ministry of Higher Education.

\section{References}

[1] R.H. Ewert, Gears and Gear Manufacture: The Fundamentals, Chapman \& Hall, 1997.

[2] H. J. Stadtfeld, Advanced Bevel Gear Technology, The Gleason Works, 2000.

[3] H. Müller, Face Hobbing vs. Face Milling, Gear Solutions, 14, pp. 49-60, 2012.

[4] H. J. Stadtfeld, Cyclocut Bevel Gear Production, Gear Solutions, 15, pp. $37-49,2012$.

[5] M. Albert, Cutting Spiral Bevel Gears On A Five-Axis Machining Center, Modern Machine Shop. 2009.
[6] Q. Fan, Computerized Modeling and Simulation of Spiral Bevel and Hypoid Gears Manufactured by Gleason Face Hobbing Process, Journal of Mechanical Design, Vol. 128, No. 6, pp. 1315-1327, 2006.

[7] A. Piazza, M.Vimercati, Experimental validation of a computerized tool for face hobbing gear contact and tensile stress analysis, Proceedings of the ASME 2007 International Design Engineering Technical Conferences \& Computers and Information in Engineering Conference, USA, pp. 1-8. 2007.

[8] T. Hiroaki, Y. Shingi, H. Akihiko, Process Development of Face Hobbing-Hypoid Gear, Mazda Technical Review, No. 23, pp. 136-141, 2005.

[9] M. Lelkes, J.Marialigeti, D. Play, Numerical Determination of Cutting Parameters for the Control of Klingelnberg Spiral Bevel Gear Geometry, ASME J. of Mechanical Design, Vol. 124: pp. 761-771, 2002.

[10] J. Astoul, J. Geneix, E. Mermoz, M. SartorA simple and robust method for spiral bevel gear generation and tooth contact analysis, International Journal on Interactive Design and Manufacturing, DOI: 10.1007/s12008-012-0163-y, 2012.

[11] R. F. Handschuh, M. Nanlawala, J. M. Hawkins, D. Mahan, Experimental Comparison of Face-Milled and Face-Hobbed Spiral Bevel Gears, NASA/TM-2001- 210940, ARL-TR-1104. 2001.

[12] S. Baolong, R. Wang, S. Hai, Research on manufacturing of a new bevel gear based on the three- axis CNC bevel gear machine, Proceedings of Mechanic Automation and Control Engineering International Conference, (MACE), pp. 6035 6037,2011

[13] X. Zhongsi, Z. Jiangtao, Modeling of machine tool for spiral bevel gear and application of tooth surface deviation correction, Proceedings of Computer Application and System Modeling (ICCASM), 2010 International Conference, Taiyuan, China, pp. V6- 240 - V6-244. 2010.

[14] S. Li, Y. Yong Wang, D. Xue,. Modelling and Simulating of Spiral Bevel Gears Based on Actual Cutting Process, Proceedings of the IEEE International Conference on Automation and Logistics, China, pp. 1694-1698. 2007. 